\title{
Análise dialógica do discurso: uma revisão sistemática integrativa
}

\author{
Alana DESTRI (1) \\ Universidade Estadual Paulista (Unesp) \\ Renata Coelho MARCHEZAN (D) \\ Universidade Estadual Paulista (Unesp)
}

\section{๖ \\ OPEN ACCESS \\ EDITADO POR \\ - Raquel Freitag (UFS) \\ AVALIADO POR \\ - Isabel Azevedo (UFS) \\ - Luciane de Paula (UNESP) \\ SOBRE OS AUTORES \\ - Alana Destri \\ Conceptualização, Análise \\ formal, Investigação, \\ Metodologia, Escrita - \\ rascunho original - e Escrita - \\ análise e edição. \\ - Renata Coelho Marchezan \\ Conceptualização, Validação e \\ Escrita - análise e edição. \\ DATAS \\ - Recebido: 31/05/2021 \\ - Aceito: 12/07/2021 \\ - Publicado: 16/07/2021 \\ COMO CITAR \\ Destri, A.; Marchezan, R. C. (2021). Análise dialógica do discurso: uma revisão sistemática integrativa. Revista da Abralin, v. 20, n. 2, p. 1-25, 2021.}

\section{RESUMO}

A análise do discurso fundamentada nos desenvolvimentos teórico-metodológicos do Círculo de Bakhtin vem sendo praticada no Brasil desde a difusão da tradução de suas obras. O termo análise dialógica do discurso (ADD), no entanto, só foi popularizado após a publicação de "Análise e teoria do discurso" de Brait em 2006 e, como tal, solidificou-se o domínio de importante e distinta área de análise do discurso. Desde então, muito se dissertou sobre sua metodologia e, com a franca expansão da área, tornase importante constituir uma revisão sistemática integrativa que investigue de forma rigorosa os conhecimentos já construídos no campo. Em vista disso, o objetivo desta pesquisa é, por meio do método de revisão citado, identificar, reunir, apreciar e sintetizar as principais contribuições das publicações teórico-metodológicas acerca da ADD, a fim de organizar as discussões metodológicas fundamentais e contribuir para possíveis direcionamentos de análise discursiva de cunho bakhtiniano. Destacaramse, assim, três principais focos metodológicos para a ADD: as relações dialógicas, os gêneros discursivos e as formas da língua. Para o estudo desses focos, mostraram-se recorrentes as atividades analíticas integradas nomeadas aqui como descrição, análise e interpretação. De modo único, tais atividades promovem o encontro constitutivo entre linguística e metalinguística na relação dialógica do objeto de estudo com o pesquisador e com outros discursos relacionáveis. Nesse processo, o ideário bakhtiniano é mobilizado de forma coerente a fim de compreender, profundamente, o enunciado concreto por meio da contínua atribuição de sentidos 


\section{REVISTA DA ABRALIN}

desenvolvidos na atuação conjunta de elementos de singularidade e estabilidade.

\section{ABSTRACT}

The discourse analysis based on the theoretical and methodological developments of the Bakhtin Circle has been practiced in Brazil since the diffusion of their works translation. The term Dialogic Discourse Analysis (DDA), however, has only become widespread after the publication of Brait's "Análise e teoria do discurso" in 2006 and, as such, it solidified an important and distinct area of discourse analysis. Since then, much has been said about its methodology and, with the booming of the area, it is important to constitute an integrative systematic review that rigorously investigates the knowledge already built in the field. In view of this, the objective of this research is, through the aforementioned review method, to identify, gather, appreciate and synthesize the theoretical and methodological publications about DDA in order to organize the fundamental methodological discussions and to contribute to possible directions of Bakhtinian discourse analysis. Thus, three main methodological foci for DDA stood out: the dialogical relations, the speech genres, and the language forms. In view of the study of these foci, the integrated analytical activities named here as description, analysis and interpretation were recurrent. In a unique way, such activities promote the constitutive encounter between linguistics and metalinguistics in the dialogical relationship of the object of study with the researcher and other relatable speeches. In this process, Bakhtin Circle's ideas are coherently mobilized in order to deeply understand the concrete utterance through the continuous attribution of meanings developed in the joint action of elements of singularity and stability.

\section{PALAVRAS-CHAVE}

Análise dialógica do discurso. ADD. Círculo de Bakhtin. Metodologia. Análise do discurso.

\section{KEYWORDS}

Dialogic Discourse Analysis. DDA. Bakhtin Circle. Methodology. Discourse analysis. 


\section{REVISTA DA ABRALIN}

\section{Introdução}

Em "O discurso em Dostoiévski”, quinto capítulo de Problemas da poética de Dostoiévski (2013), M. Bakhtin adverte, logo no início, que sua análise da obra de Dostoiévski não seria linguística no sentido tradicional do termo, mas metalinguística - ou translinguística, conforme foi utilizado por Todorov (1981). Trata-se de um estudo que considera a obra como linguagem viva, concreta, que acontece na comunicação dialógica, em enunciados, assumidos por sujeitos, que revelam suas posições, juízos.

Tal como é considerado nesse estudo de Dostoiévski e em outras obras de M. Bakhtin e do chamado Círculo de Bakhtin, o enunciado - literário ou não -, com seus interlocutores situados em contexto determinado, é único e irrepetível; no entanto, ao mesmo tempo, não é completamente novo, uma vez que se vincula, dialogicamente, a outros enunciados anteriormente realizados, juntamente com os quais provoca a realização de enunciados futuros. Desse modo, o enunciado não é tomado isoladamente, mas nessa rede de relações dialógicas de que surge e ajuda a estabelecer.

Esse reconhecimento do carácter dialógico da linguagem "[...] desempenha papel fundamental no conjunto das obras de Mikhail Bakhtin, funcionando como célula geradora dos diversos aspectos que singularizam e mantêm vivo o pensamento desse produtivo teórico" (BRAIT, 1994, p. 11).

As obras bakhtinianas, seus estudos, suas recepções, seus desdobramentos - não poderia ser diferente - compreendem uma complexa e diversificada rede de relações dialógicas, de enunciados oriundos de diferentes áreas do conhecimento ${ }^{1}$. Entre elas, interessa a este trabalho a área dos estudos da linguagem, da língua, mais particularmente, o campo dos estudos do discurso ${ }^{2}$, desenvolvidos no Brasil. Esse campo tem recebido diferentes denominações que conjugam termos relativos a discurso e à perspectiva adotada - dialógica ou bakhtiniana. Entre os termos, estão "análise dialógica do discurso", "análise dialógica de discurso", "análise dialógica dos discursos", "teoria dialógica do discurso", "teoria/análise dialógica do discurso", "análise do discurso bakhtiniana".

A análise dialógica do discurso (ADD) - denominação que se adota doravante - "[i]nstaura-se a partir da maneira como as obras escritas por Bakhtin e pelos demais membros do Círculo foram sendo conhecidas, lidas e interpretadas nas últimas décadas, particularmente no Brasil" (BRAIT, 2012a, p. 84). Portanto, não é ocioso lembrar uma baliza temporal importante da recepção brasileira das obras do Círculo. É em 1979 que os estudiosos brasileiros puderam ler pela primeira vez em português a obra Marxismo e filosofia da linguagem. Problemas fundamentais do método sociológico na ciência da linguagem (VOLÓCHINOV, 2017) ${ }^{3}$. Essa foi a primeira de muitas obras do Círculo a

\footnotetext{
${ }^{1}$ A esse respeito, ver Marchezan (2013).

${ }^{2}$ Não foram abarcados, nesta pesquisa, os trabalhos teórico-metodológicos de base bakhtiniana voltados, mais especialmente, à análise de enunciados que conjugam diferentes materialidades. É o caso, por exemplo, do enunciado verbo-visual, conforme Brait (desde 1996) e Grillo (2012), e do enunciado verbivocovisual, conforme Paula e Luciano (2020).

${ }^{3}$ Brait e Pistori (2020) expõem e avaliam a recepção dessa obra no Brasil.
} 


\section{REVISTA DA ABRALIN}

serem traduzidas para a língua do país, que já contava com a circulação das versões inglesa, publicada em 1973, espanhola, de 1976, e francesa, de $1977^{4}$.

Desde então, muitas foram as publicações acerca das contribuições teóricas do Círculo, sobre os principais conceitos teóricos que regem a metodologia dos estudos dialógicos do discurso. No âmbito das publicações traçado pelo objetivo deste trabalho, alguns desses textos foram utilizados. No entanto, ressalta-se que, embora a teoria seja indissociável da metodologia, o foco principal desta pesquisa esteve nos aspectos metodológicos.

Brait (2006b) destaca que, na perspectiva teórico-metodológica bakhtiniana, seria incompatível tanto o estabelecimento de uma proposta de análise linear ou fechada, quanto a adoção a priori de categorias aplicáveis de forma mecânica aos discursos. A contribuição do Círculo, ela ressalta, aproxima-se mais de um "[...] corpo de conceitos, noções e categorias que especificam a postura dialógica diante de corpus discursivo, da metodologia e do pesquisador" (BRAIT, 2006b, p. 61).

Averso a sistemas teóricos fechados, M. Bakhtin chama o posicionamento favorável a esses sistemas, pejorativamente, de teoricismo (BAKHTIN, 2010). Rejeita, portanto, uma aproximação ao objeto em termos positivistas, nos quais os modelos teóricos possuem pleno poder na determinação do objeto em observação (GRILLO, 2012), o que o despersonaliza e enforma em relações lógicas não dialógicas.

A metodologia bakhtiniana, portanto, não promove um método de análise em termos cartesianos, mas sim, dispõe de uma metodologia, o que, na perspectiva de Geraldi,

[...] é dispor de princípios, que precisam ser aliados à intrepidez, à astúcia, à argúcia e à perspicácia. Dispor de um método é ter corrimãos definindo a caminhada para se descobrir o que previamente se conhecia, sem expor-se ao desconhecido (2012, p. 24). ${ }^{5}$

É justamente nisso que a ancoragem de análise bakhtiniana tem um de seus maiores destaques. O conjunto das obras do Círculo permite que o pesquisador desenvolva um modo alternativo de abordar os discursos, as relações sociais, a vida, a cultura.

Considerando que, para o Círculo, todo ato de compreensão é dialógico, a postura do pesquisador diante do objeto também se diferencia da cartesiana (GERALDI, 2012). De forma alguma, aqui, o pesquisador é neutro. Na atividade científica, a relação do pesquisador com o objeto é permeada pelo seu horizonte avaliativo. Diante dele, o pesquisador é um outro não neutro que entra em diálogo com os discursos observados e com os discursos anteriormente produzidos sobre o objeto. O objeto,

\footnotetext{
${ }^{4}$ Em pesquisa no Diretório de Grupos de Pesquisa do CNPq, com método detalhado no Apêndice A, constatou-se que, pelo menos, desde 1998 se discute de forma institucionalizada análise do discurso de cunho bakhtiniano em grupos de pesquisa espalhados pelo Brasil. O termo atualmente mais utilizado para denominar a área, análise dialógica do discurso, vem sendo utilizado por Brait desde 1998 e popularizou-se após a publicação do capítulo Análise e teoria do discurso contido na obra Bakhtin conceitos-chave em 2006, texto amplamente referenciado em publicações posteriores.
}

${ }^{5}$ Ainda conforme Geraldi: "Descartes expôs um método, mas Leibniz vai dizer que Descartes, seguindo seu método, descobriu coisas interessantes, mas se outro pesquisador seguir as mesmas regras somente descobrirá o que Descartes já descobrira [...]” (GERALDI, 2012, p. 24). 


\section{REVISTA DA ABRALIN}

portanto, não é dado ou coletado, mas é expressivo, responsivo e construído na relação dialógica (BAKHTIN, 2016).

Embora não haja a pretensão de estabelecer, a partir de uma perspectiva bakhtiniana, os "corrimãos" metodológicos para toda e qualquer pesquisa, diversos autores buscaram, ao longo dos últimos anos, delinear de forma não estanque direcionamentos teóricos, metodológicos e analíticos para a ADD. Tais produções científicas avolumam-se e sua revisão sistemática integrativa, nos termos que são explicitados na próxima seção, surge como uma ferramenta adequada para investigar os estudos que marcam o desenvolvimento da área.

Ao propor essa revisão, procura-se organizar as discussões metodológicas fundamentais já realizadas e, ao mesmo tempo, busca-se contribuir para possíveis direcionamentos de análise de cunho bakhtiniano. Para tanto, enfatiza-se o objetivo desta pesquisa: por meio de uma revisão sistemática integrativa, identificar, reunir, apreciar e sintetizar as principais contribuições das publicações teórico-metodológicas acerca da área.

Como não é ainda amplamente conhecido e utilizado na área de ciências humanas, o método de revisão sistemática integrativa de literatura, com seus procedimentos, é apresentado em detalhe no tópico a seguir.

\section{Revisão sistemática integrativa de literatura}

A revisão sistemática de literatura é uma família de abordagens científicas que formam um nível secundário de análises ao recolher com métodos claros e rigorosos de pesquisa os resultados de estudos primários (NEWMAN; GOUGH, 2020). Ela difere das revisões tradicionais porque a lógica da revisão sistemática é que ela não serve simplesmente para fundamentar uma pesquisa, mas atua como uma pesquisa em si. Normalmente é desenvolvida para responder uma pergunta específica de pesquisa, para mapear alguma área do saber em busca de pontos de incerteza ou de temáticas que necessitam de mais pesquisas, bem como funciona para reavaliar questões científicas indevidamente dadas como certas (PETTICREW; ROBERTS, 2006).

Esse método como ideia toma força após a Segunda Guerra Mundial, momento em que o montante elevado e crescente de publicações científicas em determinadas áreas do conhecimento passou a preocupar os cientistas no concernente à sua avaliação e organização. Nesse cenário, a revisão sistemática surge como uma ferramenta para, inclusive, mudar paradigmas a partir da reunião e análise crítica dos trabalhos de determinada vertente sobre algum assunto específico (PETTICREW; ROBERTS, 2006).

Nessa esteira, trabalhos de revisão sistemática oferecem um importante meio de considerar a visão cumulativa engendrada por grandes e complexos corpus de análise (VICTOR, 2008). Isso além de ter um importante papel no avanço e desenvolvimento de teorias e metodologias a partir de uma visão acurada daquilo que vem sendo feito na área (PETTICREW; ROBERTS, 2006). 


\section{REVISTA DA ABRALIN}

Tal método de revisão já é amplamente utilizado na área de ciências biológicas, mas nada impede que ele seja utilizado em outras áreas do conhecimento. A revisão sistemática, inclusive, tem ganhado espaço e encontra-se em pleno desenvolvimento de métodos cada vez mais adequados para revisões de pesquisas qualitativas em ciências humanas (VICTOR, 2008). Isso porque "[...] a revisão sistemática é uma técnica eficiente para o teste de hipóteses, para resumir os resultados dos estudos existentes e para avaliar a consistência entre estudos anteriores. Essas tarefas não são exclusivas da medicina" ${ }^{n 6}$ (PETTICREW; ROBERTS, 2006, p. 267. Tradução nossa).

A revisão sistemática, segundo Victor (2008), embora tenha mantida sua base procedural, possui vertentes de acordo com as formas e necessidades de emprego, a saber, a tradicional, muito usada para os interesses da medicina clínica; a estendida, semelhante à tradicional com adaptações para expandir sua aplicabilidade fora da área médica, e a integrativa, vertente utilizada no presente trabalho.

A revisão sistemática integrativa desenha a aproximação com a literatura a partir da ideia de que o conhecimento deve ser construído de forma integrativa, não acumulativa. Tem, portanto, como foco principal a sofisticação e avanço de teorias, o que ocorre em movimento interativo (VICTOR, 2008).

Diferentemente da abordagem de revisão sistemática tradicional, a revisão sistemática integrativa favorece as demais áreas ao permitir a revisão conjunta de diversos tipos de dados e de pesquisas com variadas estruturas. Comporta, também, o ponto de vista de que a realidade física é mediada pelo sociocultural em diversos níveis da experiência humana. Por conseguinte, a revisão integrativa toma para si o elemento do rigor da revisão sistemática tradicional ao mesmo tempo em que abre as possibilidades de resposta para o que funciona, para quem e em que circunstâncias, indo além do limitado o que funciona relacionado ao paradigma positivista (JONES-DEVITT; PARKIN, 2017).

No caso deste trabalho, a revisão não se centra em pesquisas quantitativas, mas na revisão sistemática integrativa das publicações teóricas que buscam, de alguma forma, desenvolver ou clarificar os caminhos para uma análise dialógica do discurso, área cunhada em solo brasileiro que se desenvolve a passos rápidos, com cada vez mais adeptos. A síntese dos resultados, portanto, não foi exposta em termos estatísticos, mas a partir de uma síntese narrativa que aproxima e aprecia as ideias dos diversos autores envolvidos.

\section{1 Os procedimentos da revisão sistemática integrativa}

Tendo em vista que a descrição dos procedimentos metodológicos é parte indispensável para compor a clareza que exige uma revisão sistemática integrativa, esta seção detalha o processo.

\footnotetext{
${ }^{6}[. .$.$] the systematic review is an efficient technique for hypothesis testing, for summarizing the results of existing studies, and for$ assessing consistency among previous studies. These tasks are not unique to medicine.
} 


\section{REVISTA DA ABRALIN}

1.1.1 Planejamento do protocolo

Uma revisão sistemática exige, invariavelmente, a especificação de um objetivo de pesquisa e os métodos que serão utilizados para investigar o objeto. Para tanto, é necessária a elaboração cuidadosa de um protocolo que guiará rigorosamente o estudo (NEWMAN; GOUGH, 2020).

Nesta primeira fase, o objetivo da pesquisa foi definido - identificar, reunir, apreciar e sintetizar as principais contribuições das publicações teórico-metodológicas acerca da área de ADD. Com isso, selecionou-se como databases (base de dados) as possivelmente maiores em volume de informação da área: Google Acadêmico ${ }^{7}$, Portal de Periódicos $\operatorname{Capes}^{8}$ e $\mathrm{SciELO}^{9}$ para a busca de artigos científicos; e Google Books ${ }^{10}$, Portal de Periódicos Capes (livros), SciELO Livros ${ }^{11}$ e Wordcat ${ }^{12}$ para busca de publicações em livro.

A revisão sistemática deve operar de forma bem discriminada. Assim sendo, o desenvolvimento de regras sobre que publicações serão elegíveis para a revisão é indispensável. O critério de seleção - tanto de inclusão, quanto de exclusão - cria restrições para que a revisão seja exequível e atenda de forma direta ao objetivo de pesquisa (NEWMAN; GOUGH, 2020).

Os critérios de seleção e qualidade desenvolvidos para máxima abrangência de produções relevantes foram, aqui, desenvolvidos em cinco áreas: conteúdo, idioma e gênero de publicação:

a) Conteúdo: foram excluídas as publicações nas quais o objetivo central não estava relacionado ao objetivo desta pesquisa. Ou seja, não foram consideradas publicações que não tinham como objetivo central dissertar e/ou ampliar a discussão sobre elementos teóricos-metodológicos da ADD. Trabalhos que demonstravam ter como eixo principal a realização da ADD perante algum objeto em específico, que não direcionavam seus estudos para o discurso verbal e que visavam contrastar a ADD com outras linhas não foram incorporados.

b) Idioma: para ser selecionado, o produto acadêmico deveria estar em português. Com isso pretendeu-se dar destaque para o desenvolvimento expressivamente brasileiro da ADD e sua repercussão em língua portuguesa.

c) Publicações: foram incorporados capítulo de livros de editoras científicas e periódicos que publicaram sob o regime de revisão por pares.

d) Período: a busca deu-se sem data limite inicial, a fim de incorporar as primeiras discussões divulgadas amplamente sobre o foco desta revisão. A data limite final é a da busca: 30 de março de 2021.

\footnotetext{
${ }^{7}$ https://scholar.google.com.br/

${ }^{8}$ https://www-periodicos-capes-gov-br.ezl.periodicos.capes.gov.br/

${ }^{9}$ https://scielo.org/

${ }^{10}$ https://books.google.com.br/

${ }^{11}$ http://books.scielo.org/

${ }^{12}$ https://www.worldcat.org/
} 


\section{REVISTA DA ABRALIN}

O objetivo da revisão tem influência sobre os critérios de seleção. Os critérios, por sua vez, determinam como será a estratégia de pesquisa nas bases de dados científicos (NEWMAN; GOUGH, 2020). Assim sendo, como o último elemento do planejamento de protocolo, definiu-se a string (linha de busca) com o auxílio dos operadores booleanos ${ }^{13}$. A linha de busca geral contém os seguintes termos a serem encontrados nos títulos das publicações: "Análise dialógica do discurso" OR "Análise do discurso bakhtiniana" OR "Análise de discurso bakhtiniana" OR "Análise bakhtiniana" OR "Teoria bakhtiniana" OR "Análise dialógica" OR "Teoria dialógica" OR "Perspectiva dialógica".

Como é de se esperar, cada uma das bases de dados elencadas para esta pesquisa apresenta funcionalidades diferentes. Embora a string geral tenha se mantido, a estratégia de busca variou sensivelmente entre elas, como pode ser visto em detalhe no Apêndice A. Quando possível, foi adicionado à pesquisa uma segunda linha de busca para atuar de forma combinada com a primeira: Metodologia OR Método OR Prática OR Metodológico OR Metodológica OR Teórico-metodológico OR Teórico-metodológica OR Epistem* OR Parâmetro. Quando não foi possível combiná-las, a busca nas bases de dados seguiu com a primeira string e a combinação com os termos da segunda string foi observado manualmente.

Para serem considerados, os artigos resultantes da busca deveriam conter, entre os campos do título, resumo e palavras-chave, obrigatoriamente, pelo menos uma das expressões arroladas na primeira string em simultaneidade com pelo menos uma das palavras elencadas na segunda string. Como livros e capítulos não possuem resumo, se o título de uma obra bakhtiniana apresentasse qualquer um dos termos da primeira ou segunda string, passavam para a fase de averiguação do sumário e textos integrais para avaliação temática. ${ }^{14}$ Desse modo, fica claro que o escopo da pesquisa são os trabalhos em ADD que destacam a questão da metodologia; ficam de fora, portanto, os inúmeros trabalhos dedicados à análise do discurso, propriamente dita.

\subsubsection{Busca e seleção}

Depois de efetivada a pesquisa, um grande número de títulos foi retornado - nem todos relevantes para a revisão. Portanto, cada um deles foi analisado, a fim de que, pelo processo de checagem, restassem apenas os que se encaixam nos critérios de seleção desenvolvidos anteriormente (NEWMAN; GOUGH, 2020). A avaliação crítica do que será incorporado é absolutamente importante para garantir a confiabilidade da revisão sistemática. Nesta pesquisa, ela aconteceu em três etapas eliminatórias: 1) seleção a partir do título; 2) seleção a partir do resumo; 3) seleção a partir da leitura do texto integral. O quadro que destaca o processo de busca e seleção é o Apêndice A.

\footnotetext{
${ }^{13}$ São operadores como AND, OR, NOT AND, e XOR que funcionam a partir da lógica booleana, um sistema algébrico criado por George Brooks. São utilizados, principalmente, em pesquisas em databases (ZOHURI; MOGHADDAM, 2017).

${ }^{14}$ O capítulo Análise e teoria do discurso de Beth Brait (2006a) foi incluído no corpus como única exceção ao protocolo, dado o caráter fulcral dessa obra para a análise dialógica do discurso.
} 


\section{REVISTA DA ABRALIN}

Os resultados de busca de livros e capítulos foram baixos, o que nos leva a crer que não há uma database satisfatoriamente ampla acerca das publicações em livros no Brasil. Outra dificuldade esteve no fato de que nem todos os artigos que focam em questões metodológicas explicitam isso no título ou nas palavras-chaves, o que dificulta o acesso do pesquisador interessado e a incorporação na pesquisa.

Assim, para que houvesse uma cobertura maior das obras, lançou-se mão de uma busca complementar, para artigos, livros e capítulos, no Diretório de Grupos de Pesquisa do CNPq (DGP) ${ }^{15}$, com estratégia de busca também detalhada no Apêndice A. Embora a pesquisa tenha sido de maneira manual, pela visita dos currículos Lattes dos pesquisadores, as palavras de busca e os critérios de seleção foram considerados de forma rigorosa, nos moldes das pesquisas em database. Ressalta-se também que, assim como o previsto para os resultados das databases, os livros que continham no título pelo menos um dos termos de busca tiveram todos seus capítulos investigados. Logicamente, entraram no corpus apenas os considerados interessantes ao objetivo desta revisão.

Os procedimentos de busca foram finalizados depois de toda a aplicação do protocolo e depois dos demais esforços de busca não retornarem nenhum dado novo, com a confiança de que o número de artigos e capítulos de livro considerado é suficiente para uma revisão integrativa representativa.

Ao final dos processos de seleção e da aplicação dos critérios definidos, foram contabilizados 30 textos - 16 artigos científicos e 14 capítulos de livros. Esses estudos foram organizados de forma cronológica crescente, conforme se pode visualizar no Apêndice B.

\subsubsection{Codificação e avaliação}

Com as publicações relevantes em mãos, cada uma é lida e, nela, é feita a identificação, seleção e categorização sistemática das informações pertinentes para responder ao objetivo da revisão. A essa atividade dá-se o nome de codificação e, às categorias emergentes, dá-se o nome de códigos. $\mathrm{O}$ processo pode começar com alguns códigos pré-definidos e, de forma dedutiva, se pode codificar o corpus conforme questões interessantes à pesquisa surjam (NEWMAN; GOUGH, 2020). No caso desta, as categorias de codificação foram elaboradas ao longo da leitura, sem códigos pré-definidos, de acordo com as informações teórico-metodológicas dos textos selecionados. Buscou-se encontrar temas recorrentes nos textos e indicações teórico-metodológicas-analíticas que lançassem luz ao aspecto prático da análise dialógica.

A partir da primeira codificação dos dados, revisou-se cada um dos trechos codificados a fim de compreender se a codificação fora feita de maneira adequada. O procedimento seguinte foi buscar compreender a relação entre os códigos e agrupar os de função semelhante. O corpo dos códigos categorizados, por fim, representa as mais relevantes orientações para uma efetiva análise dialógica do discurso desenvolvidas pelos autores do corpus.

\footnotetext{
${ }^{15} \underline{\mathrm{http}}$ ///lattes.cnpq.br/web/dgp/
} 


\section{REVISTA DA ABRALIN}

1.1.4 Sintese narrativa

A síntese de uma revisão sistemática integrativa é mais do que uma simples lista, um apanhado de dados encontrados em pesquisas primárias, expediente muitas vezes encontrado em revisões sistemáticas tradicionais. O objetivo dessa fase é integrar as informações dos estudos individuais para produzir uma resposta sobre a questão em foco mais desenvolvida do que a que é dada pelos estudos individuais. Para chegar a esse ponto, é necessária a leitura e releitura de cada um dos textos selecionados, a elaboração de codificação descritiva e analítica além da constante comparação para fins de avanço do tema em questão. Com isso, a revisão sistemática está pronta para ser reportada (NEWMAN; GOUGH, 2020).

O método de síntese utilizado na revisão sistemática integrativa normalmente é o narrativo, o que envolve descrever os resultados sintetizados e estruturados narrativamente, sempre de modo conectado a um quadro de resultados-chave. Além disso, mostra-se adequada à revisão integrativa uma síntese temática, que foca explicitamente na vinculação de temas a fim de desenhar um quadro ou modelo teórico (VICTOR, 2008).

O próximo tópico apresenta a síntese narrativa, temática e não exaustiva, estabelecida a partir da incidência dos códigos que se pode depreender do exame da relação entre os documentos selecionados. A incidência dos códigos depreendidos pode ser visualizada no quadro de resultadoschave (Apêndice B). Pode-se adiantar que, no quadro, a não marcação de um determinado código não significa que o tema não figure no texto como um todo. Significa, apenas, que o assunto não foi desenvolvido com destaque. Tais dados foram, então, interpretados para o desenvolvimento de sentidos apresentado na síntese narrativa desta revisão.

\section{Síntese narrativa da revisão sistemática integrativa: ADD}

Como mencionado anteriormente, as obras do Círculo não firmaram um conjunto fechado de normas e procedimentos para o tratamento do discurso, no entanto, compreendem princípios e direcionamentos para tal abordagem metodológica. Dentre as obras do Círculo citadas nos trabalhos sobre a metodologia na ADD, a que mais ganhou destaque foi Marxismo e filosofia da linguagem de V. Volóchinov. Mais precisamente, citou-se o trecho do capítulo "A interação discursiva", em que aparece uma sequência metodológica. Reproduz-se, abaixo, a citação, utilizando a tradução brasileira de 2017, embora os trabalhos anteriores a essa data tenham se utilizado da tradução então disponível, de 1979, em que, dentre outras diferenças, aparece "categorias de atos de fala" no lugar de "gêneros dos discursos verbais":

[...] a ordem metodologicamente fundamentada para o estudo da língua deve ser a seguinte: 1) formas e tipos de interação discursiva em sua relação com as condições concretas; 2) formas dos enunciados ou discursos verbais singulares em relação estreita com a interação da qual são parte, isto é, os gêneros dos discursos verbais determinados pela interação discursiva na vida e na criação ideológica; 3) partindo disso, revisão das formas da língua em sua concepção linguística habitual (VOLÓCHINOV, 2017, p. 220). 


\section{REVISTA DA ABRALIN}

O desenvolvimento das proposições metodológicas no corpus investigado configurou-se, em grande parte, em torno desses três focos de estudo elencados na citação acima, que, mais resumidamente, foram nomeados aqui: 1) relações dialógicas; 2) gêneros do discurso; e 3) formas da língua. Esses elementos ganham maior desenvolvimento nos tópicos que seguem, a partir das reflexões teórico-metodológicas dos autores dos textos selecionados para a revisão sistemática. Como motriz teórico-metodológica, esses parâmetros, em comunhão com a arquitetônica da obra do Círculo, inspiraram procedimentos que foram reunidos e sintetizados em três grandes campos de ordem prática: descrição, análise e interpretação. Essas atividades analíticas encontram-se explicitadas após os desdobramentos dos focos de estudo. Em ambos os tópicos, as referências utilizadas estão circunscritas aos trabalhos que compõem o corpus.

\subsection{Focos de estudo}

Este segmento da síntese narrativa evidencia a abordagem metodológica singular dada pelos autores do corpus sobre cada um dos três focos de estudo destacados anteriormente.

\subsubsection{Relações dialógicas}

Tendo uma concepção de linguagem histórico-social-cultural, a ADD considera que língua, linguagens, história e sujeitos estão sempre em ligação íntima (BRAIT, 2012a). Assim sendo, Sobral e Giacomelli (2016) lembram que essa abordagem discursiva parte da linguagem efetivamente realizada, isto é, concebe como unidade de análise o enunciado concreto. Tal enunciado é indissociável da subjetividade, da ética e do evento (MENDONÇA, 2012).

Ao tratarem de relações dialógicas, Oliveira, Huff e Acosta Pereira (2019), destacam a afirmação de M. Bakhtin de que "[q]uanto a mim, em tudo ouço vozes e relações dialógicas" (BAKHTIN, 2003, p. 410). Isso implica o exame das relações dialógicas da corrente ininterrupta de enunciados concretos, das vozes que reverberam na produção de sentidos. Sendo as relações dialógicas o objeto principal da metalinguística (BRAIT, 2006b), é de se esperar que perpassem todos os outros focos e atividades analíticas do discurso.

Brait (2006b) afirma, em menção a M. Bakhtin, que as relações dialógicas, embora extralinguísticas, não podem ser compreendidas fora do campo discursivo. Essas relações situam-se entre os sujeitos e desenvolvem-se ao passo que estes constroem e são construídos pelos enunciados. Tal estudo por meio de enunciados concretos, destaca Alves (2019), requer a recuperação do caráter histórico constituinte e constitutivo das diversas formas de movimento linguístico presentes em todas as esferas de atuação humana.

Ruiz (2017) reforça que as relações dialógicas são plenas de projeções e posicionamentos valorativos e ideológicos. Portanto, o homem social só pode ser observado e compreendido por meio dos enunciados - verbais ou não - que constituem e pelos quais são constituídos. Dessa observação, os 


\section{REVISTA DA ABRALIN}

sentidos são forjados "[...] no confronto de duas consciências, de dois interlocutores, de conjunção de discursos histórica, cultural e socialmente situados" (BRAIT, 2012b, p. 15).

Oliveira, Huff e Acosta Pereira (2019), ao lidarem com as ideias de P. Medviédev, ampliam essa noção afirmando que, nessas condições, estudar o discurso envolve também atentar-se à cultura, entendida como fenômeno vivo e aberto que, por meio dos enunciados concretos - e de suas formas relativamente estáveis, os gêneros do discurso -, é passível de morte e renovação.

\subsubsection{Gêneros do discurso}

Postulada a importância das relações dialógicas para o estudo do discurso e, portanto, de todos os gêneros discursivos, solidifica-se a ideia de que a língua não é ato individual, mas de comunhão responsiva que desenvolve a constituição história e social dos sujeitos, como sublinha Gedoz (2015).

Ao abordar os gêneros do discurso, Rodrigues (2004) afirma que eles podem figurar como principal objeto de investigação ou servir como critério para delimitar o estudo. Em outras palavras, pode-se estudar um fenômeno linguístico ou enunciativo privilegiando as configurações que o vinculam a seu gênero discursivo.

Miotello (2012), em linha semelhante de pensamento, destaca que a compreensão da situação genérica de determinado enunciado promove grande abertura para a compreensão de sentidos. Acosta Pereira e Oliveira (2020) reforçam que é pelo gênero discursivo que se observam as circunstâncias de determinada esfera de comunicação, visto que essas formas tipificadas de discurso se desenvolvem e se reorganizam acompanhando-as. Nessa dinâmica, os gêneros refletem e refratam novas facetas da realidade sociopolítica que, anteriormente, não se encontravam disponíveis.

Estes últimos autores trazem também o conceito bakhtiniano de cronotopo como porta de entrada para os estudos dos gêneros. Tal conceito reforça a indissolubilidade entre os acontecimentos espaço-temporais e as formas de discurso. Os gêneros sempre respondem ao horizonte valorativo de um grupo e moldam-se às compreensões sócio-histórico-culturais da época, o que viabiliza atenção social a um conjunto específico de objetos.

Destarte, os gêneros do discurso, como prática discursiva sempre vinculada às práticas sociais, são examinados juntamente com a consideração dos contextos de manifestação e intercâmbio social dos discursos. Pois isso, como reiteram Sobral e Giacomelli, é "[...] passo importante para o dimensionamento do ser e do agir sociais da linguagem" (SOBRAL; GIACOMELLI, 2018, p. 315).

Isso posto, o estudo do gênero do discurso é parte fundamental do que Brait chama de semente da ADD:

[...] é reconhecer o gênero a que pertencem os textos e os gêneros que nele se articulam, descobrir a tradição das atividades em que esses discursos se inserem e, a partir desse diálogo com o objeto de análise, chegar ao inusitado de sua forma de ser discursivamente, à sua maneira de participar ativamente de esferas de produção, circulação e recepção, encontrando sua identidade nas relações dialógicas estabelecidas com outros discursos, com outros sujeitos (BRAIT, 2012a, p. 87-88). 


\section{REVISTA DA ABRALIN}

As relações dialógicas estabelecidas, além de serem examinadas a partir de enunciados e de suas formas relativamente estáveis, também são investigadas a partir da materialidade da língua em sua concepção habitual, como se trata a seguir.

\subsubsection{Formas da língua}

Em uma análise dialógica, metalinguística, é preciso atentar à materialidade do texto. Os recursos linguístico-gramaticais que constituem o enunciado são também selecionados e mobilizados ideologicamente, de acordo com o horizonte valorativo de um grupo. As escolhas lexicais, inclusive, "[...] demarcam as amplitudes do cronotopo na medida em que determinadas palavras passam a constituir signos ideológicos, refletindo e refratando a realidade social" (ACOSTA PEREIRA; OLIVEIRA, 2020, p. 253).

Brait defende que a metalinguística herda da linguística

a possibilidade de esmiuçar campos semânticos, descrever e analisar micro e macro-organizações sintáticas, reconhecer, recuperar e interpretar marcas e articulações enunciativas que caracterizam os discursos e indiciam sua heterogeneidade constitutiva assim como de seus sujeitos (BRAIT, 2012a, p. 87).

Isso se deve ao entendimento que se tem, na $\mathrm{ADD}$, de que a linguagem tem dois componentes: o formal e o discursivo. O formal liga-se, dentre a outros elementos estruturais da língua-sistema, às significações do dicionário. Em contrapartida, o componente discursivo atém-se à enunciação e aos sentidos produzidos, não dados. Ambos os componentes formam um todo inseparável. Não há discurso sem língua, do mesmo modo que o uso da língua - discurso - não pode ser compreendido por completo sem considerar que é nas relações extralinguísticas que os sentidos são constituídos (SOBRAL; GIACOMELLI, 2016).

Para o Círculo, o estudo interior da língua como sistema, o tratamento apenas das categorias gramaticais, não é suficiente para o exame do enunciado em sua instância social. É a partir da relação entre o linguístico e o extralinguístico que se tem acesso ao discurso. Portanto, estudar apenas um dos componentes é deslocar-se da noção de enunciado. Para Sobral e Giacomelli (2018), a forma e o conteúdo textual se ligam de modo inseparável à realidade material. Com isso em mente, os autores apontam para a observância de "[...] mecanismos e estratégias discursivos dominantes no discurso dado; a sequência na qual se distribuem esses mecanismos no discurso; e as inter-relações entre esses mecanismos" (SOBRAL; GIACOMELLI, 2018, p. 320).

Em suma, na análise dialógica há, sim, análise das marcas linguísticas. No entanto, a abordagem que se dá à língua é discursiva. É uma análise do funcionamento da língua em uso, uma análise que leva em consideração o extralinguístico, o histórico e o concreto, tudo materializado nos enunciados (ROHLING, 2014).

Como pôde ser observado, os três focos - relações dialógicas, gêneros do discurso e formas da língua - se interpenetram, sendo impossível estudar um sem levar em consideração os outros. Mesmo que se possa considerar que V. Volóchinov tenha proposto uma relação de ordem dos focos de análise, tem se mostrado ponto pacífico que o estudo de determinado objeto pode acontecer em 


\section{REVISTA DA ABRALIN}

ordem diversa, desde que abranja todos os focos. A partir da revisão sistemática, entende-se ainda que a unidade dos focos de estudo comporta as atividades analíticas de descrição, análise e interpretação. Embora esses termos articulados só figurem, no corpus, de modo explícito nos textos de Sobral (2014) e Sobral e Giacomelli (2016; 2018), observou-se que tais atividades foram promovidas de forma recorrente ao longo dos textos selecionados, com a finalidade de abordar os focos mencionados.

\subsection{Atividades analíticas}

Os textos metodológicos desta revisão levam à consideração de que a atividade analítica contempla em si outras duas atividades além da análise propriamente dita: descrição e interpretação. Essas três atividades - descrição, análise e interpretação - são complementares e inseparáveis. Considera-se que a descrição é a primeira aproximação do objeto que se quer examinar - o pesquisador ocupa-se de apresentar o objeto em seus elementos que dão conta de sua configuração geral e específica; a análise é a prática teórica sobre o enunciado concreto; e a interpretação é elemento que permite que a análise receba de forma especial o posicionamento embasado do estudioso, é a atividade que possibilita o estabelecimento de sentido das relações promovidas na análise.

Em vista disso, esta seção está dividida em descrição, análise e interpretação com a única função de clarificar o modo como tais procedimentos estão sendo conduzidos no campo da ADD. Aqui, concorda-se com Sobral (2014): a indicação dessas três atividades serve para melhorar o aproveitamento dos instrumentos de análise ao passo das demandas metodológicas do objeto em observação.

Para não induzir uma mecanização desses procedimentos de análise, é necessário ressaltar que eles não se desenvolvem em sucessão, como etapas apartadas umas das outras. Nenhum dos autores citados neste artigo advoga em favor de uma divisão de procedimentos ou faz clara distinção entre os processos de análise porque, na integridade do ato concreto, tal divisão não há. Caso a unicidade da análise não seja respeitada, isso resultaria em uma artificialidade mecânica que empobreceria e, possivelmente, destituiria o caráter dialógico da análise. Reforça-se, então, que as atividades analíticas descrição, análise e interpretação só foram assim explicitadas neste artigo para fins de clareza didática.

Também é importante deixar claro que, embora a nomenclatura apresentada aqui ecoe a utilizada por Sobral (2014) em cocriação com Brait, não se teve o objetivo de replicar ou ampliar conceitualmente a interessante contribuição desses autores. Do mesmo modo, não significa necessariamente que os autores citados a seguir desenvolvam suas ideias sobre descrição, análise e interpretação a partir das orientações de Sobral e Brait. O detalhamento feito aqui das atividades apresenta como cada um dos autores do corpus compreende as tarefas de descrição, análise e interpretação em uma perspectiva bakhtiniana. O resultado é uma amálgama de muitas vozes, relativamente estável, que de forma alguma é - e nem pretende ser - uníssona. 


\section{REVISTA DA ABRALIN}

\subsubsection{Descrição}

Sobral (2014) considera a atividade de descrição o primeiro contato com o objeto a ser analisado. É momento de observação da esfera de produção, circulação e recepção dos enunciados concretos do corpus, aliados aos gêneros do discurso no qual se inserem. Investigam-se também o suporte de veiculação e, de modo preliminar, os aparentes elementos de variância e invariância entre os enunciados selecionados para o estudo. É também neste momento da atividade analítica que se atenta à descrição da especificidade do corpus no que tange ao tema, estilo e construção composicional de seu gênero, juntamente a outros elementos possivelmente interessantes para a execução das próximas atividades analíticas.

Ao descrever, o analista explora a unidade de seu objeto em sua materialidade composta pela camada linguística e a enunciativa (SOBRAL; GIACOMELLI, 2016). Scherma e Turati (2012) recomendam a observação de escolhas lexicais, expressões, formas gramaticais e a disposição desses elementos no todo do enunciado. Indo para além da base linguística, os autores atentam para a importância da observação da situação comunicacional e as relações dialógicas entre os sujeitos que participam e configuram a interação. A entonação expressiva do enunciado, o posicionamento social dos sujeitos e o posicionamento do enunciador frente ao outro também são aspectos relevantes a serem descritos.

Esses sujeitos socialmente organizados estão situados, evidentemente, em uma esfera da atividade humana. Para enfocá-la, Rohling (2014) sugere algo semelhante ao proposto por Scherma e Turati: a descrição dos posicionamentos assumidos em interação discursiva, com destaque para as relações simétricas ou assimétricas indexadas no modo de produção enunciativa; a observação do espaço-tempo discursivo em que se desenvolveu a ação comunicativa; e o estudo do horizonte temático-valorativo instaurado nos enunciados.

Pensando na descrição como primeiro contato, diversos teóricos sinalizam a necessidade de deixar o corpus se revelar, e não olhar para o objeto a partir de categorias pré-estabelecidas (BRAIT, 2006a; GERALDI, 2012; OLIVEIRA; HUFF; ACOSTA PEREIRA, 2019; PAULA, 2013; PAULO; MOREIRA, 2012; ROHLING, 2014; RUIZ, 2017; SANTOS; ALMEIDA, 2012; SOBRAL; GIACOMELLI, 2018; STAFUZZA, 2019).

Nas palavras de Sobral e Giacomelli, “[...] cada discurso específico autoriza um dado conjunto de elementos analíticos a ser mobilizado em seu exame" (SOBRAL; GIACOMELLI, 2018, p. 307). Assim sendo, não há categorias prévias a serem aplicadas de forma direta à análise do texto. O que existe são parâmetros norteadores, orientações, conforme se expôs nesta revisão integrativa. Cada enunciado examinado possui uma especificidade que aponta para os elementos que podem ser mais adequados para a análise. Os conceitos bakhtinianos a serem mobilizados partem justamente desse diálogo com o objeto de pesquisa. É esperado que o pesquisador deixe "[...] que os discursos revelem sua forma de produzir sentido, a partir do ponto de vista dialógico, num embate" (BRAIT, 2006a, p. 24).

Isso tudo pouco serve se a descrição não tiver o objetivo de, ao ser levada para as outras atividades da análise, promover a explicação do fenômeno discursivo em foco, conforme enfatiza Lima (2014). Espera-se que uma descrição seja feita sempre almejando as contribuições que pode dar na construção de sentidos do discurso. Isto é, tendo em vista que é o objeto que determina o que é 


\section{REVISTA DA ABRALIN}

relevante ser descrito, o objetivo da ADD é explicar o objeto e não o enquadrar. Além disso, cada descrição faz um recorte que marca a construção do objeto. Portanto, é necessário que a promoção dessa atividade seja clara para que o enunciado possa falar e não ser simplesmente modelado pelo pesquisador (SOBRAL; GIACOMELLI, 2018).

Se, nesse primeiro contato, o analista sucumbir ao ímpeto de uma interpretação direta, grandes são os riscos de tecer conclusões que, no íntimo, são simples impressões (SOBRAL, 2014). Recomenda-se, então, que a descrição dos focos de análise - ou de alguma conexão específica entre eles - articule-se a uma análise embasada.

\subsubsection{Análise}

É na atividade de análise que se observa de forma cuidadosa a unidade arquitetônica dos elementos enunciativos e discursivos, desenvolvendo possíveis relações, identificando subtemas e fundamentando, mediante as formas da língua mobilizadas, os componentes extralinguísticos do corpus (SOBRAL, 2014). Além disso, a conjuntura do arcabouço teórico bakhtiniano deve ser mobilizada de modo coerente, visto que os conceitos desenvolvidos pelo grupo não foram concebidos de forma isolada, mas em diálogo (ACOSTA PEREIRA; OLIVEIRA, 2020). Os conceitos do Círculo - filosóficos, linguísticos, enunciativos, discursivos - ganham significado e corpo na medida em que são articulados com os demais, nunca isoladamente (BRAIT, 2012b).

Nesse ensejo, cabe ao pesquisador, em postura dialógica com o objeto, descobrir caminhos para melhor atender às suas necessidades analíticas. Em atenção a isso, Brait ressalta a pertinência desse tipo de análise:

[a] pertinência de uma perspectiva dialógica se dá pela análise das especificidades discursivas constitutivas de situações em que a linguagem e determinadas atividades se interpenetram e se interdefinem e do compromisso ético do pesquisador com o objeto que, dessa perspectiva, é um sujeito histórico (BRAIT, 2006b, p. 61).

O compromisso entre o pesquisador e o objeto implica, entre outras coisas, uma relação de empatia - de colocar-se no lugar do outro estudado -, mas não se restringe a isso. A garantia de um conhecimento aprofundado é o retorno do pesquisador para seu horizonte avaliativo singular após o contato empático que manteve (OLIVEIRA, HUFF, ACOSTA PEREIRA, 2019). É um contato de enriquecimento mútuo que se baseia na dinâmica entre dois pontos de vista internos e externos. Silenciar um deles é privar-se do proposto pela teoria do Círculo, é privar-se do posicionamento dialógico que caracteriza a ADD (BRAIT, 2012b). Em referência à Marilia Amorim, Rodrigues (2015) ressalta que o pesquisador sempre deve reconhecer que, por maior que seja sua proximidade com o objeto, o fato de estudá-lo coloca o objeto em posição de desconhecido, de estrangeiro. Em um processo alteritário, o pesquisador promove encontros com o objeto de modo a fazê-lo falar, de ouvi-lo, de compreendê-lo, de traduzi-lo, de influenciá-lo, de deixar-se influenciar por ele. 


\section{REVISTA DA ABRALIN}

No procedimento de análise, especialmente, é interessante para o pesquisador a investigação das relações dialógicas no modo como "[...] apontam para a presença de assimilação de discursos já-ditos e discursos prefigurados, discursos bivocais, apagamentos de sentidos, contraposições, enquadramentos, reenunciação de discursos e reacentuações de discursos" (ROHLING, 2014, p. 50). Desse modo, o percurso metodológico parte da premissa de que a unidade analítica responde a enunciados anteriores e antecipa enunciados posteriores. Portanto, é imprescindível estabelecer a dependência recíproca do enunciado em questão com relação à cadeia enunciativa na qual está situado (STAFUZZA, 2019).

Nesse contato dialógico com o objeto, além da voz do pesquisador aproximar o discurso em estudo de outros relacionáveis, faz emergir outras vozes que dão profundidade ao discurso. Em consequência, o discurso abre-se para novas interpretações. Geraldi (2012) considera esse movimento cotejo, desenvolvendo a noção posta por M. Bakhtin (2003). Essa noção também é citada por Rohling (2014), Rodrigues (2015), Pereira (2017), Fanini (2019) e Alves (2019).

Geraldi acredita que, para se desvendar os sentidos de um texto, antes é preciso cotejá-lo com outros, visto que é pela multiplicidade de vozes que se compreende o enunciado concreto em sua unicidade. Para ele, cotejar é também recuperar parcialmente a cadeia infinita de enunciados que respondem e são respondidos por outros (GERALDI, 2012).

Ao se cotejar, ainda na perspectiva de Geraldi, vai-se "[...] elaborando conceitos ou reutilizando conceitos produzidos em outros estudos (até mesmo em outros campos) com que se aprofunda a penetração da obra em estudo" (GERALDI, 2012, p. 33). A tese resultante desse processo analítico forma-se por raciocínios aditivos e, desse jeito, os sentidos construídos são infindáveis (GERALDI, 2012). Destarte, uma análise dialógica do discurso não tem a pretensão de ser $a$ análise: é uma análise - rigorosa e fundamentada, mas não fechada (FANINI, 2019). Cabe ao pesquisador, portanto, dar limite à análise de acordo com os objetivos de estudo previamente delineados.

Em composição às questões apresentadas, Lima (2014) atenta para o fato de que uma análise dialógica pretende ser uma análise de processo e não de produto. Trazendo o psicólogo Lev Vigotski para somar na discussão de metodologia, Lima argumenta que uma análise de produto, que tende ao estático, satisfaz-se com a identificação e segmentação do que compõe o objeto de análise. A análise do processo, por outro lado, reconhece o objeto como dinâmico, tornando relevante a investigação de pontos de mudanças na constituição de sua história. O norte investigatório seria, assim, explicar o que leva o objeto a ser o que é e o que o leva a se transformar como se transforma.

O próximo e último segmento desta síntese narrativa compreende o processo de construção de sentidos a partir das relações teóricas feitas em análise.

\section{2 .3 Interpretação}

A atividade da interpretação promove a reunião dos dados desenvolvidos e dos conceitos movimentados em análise para a definição da especificidade do objeto e de sua relevância em determinado universo (SOBRAL, 2014). Há, para tanto, a observação dos sentidos construídos a partir dos aspectos de singularidade e relativa estabilidade do corpus. 


\section{REVISTA DA ABRALIN}

A valorização da intepretação do caráter singular do discurso pode ser observada em Acosta Pereira e Rodrigues (2010), Brait (2006a), Brait (2006b), Figueiredo e Trevizan (2012), Geraldi (2012), Santos e Almeida (2012), Mendonça (2012), Brait (2012b), Oliveira, Huff e Acosta Pereira (2019), Paula (2013) e Rohling (2014). Isso significa admitir como passível de ser tratado cientificamente o enunciado único, irrepetível, rejeitando a ideia tradicional de que o irregular é um "desvio" cientificamente não significativo. Assim, há a implicação de que o pesquisador reconheça "[...] a infinitude do processo dialógico, em que todo dizer e todo dito dialogam com o passado e o futuro, e paradoxalmente deve reconhecer a unicidade e irrepetibilidade dos enunciados produzidos em cada diálogo" (GERALDI, 2012, p. 20).

A valorização do gesto interpretativo sobre a relativa estabilidade dos enunciados que compõem o corpus, por sua vez, é ressaltada por Brait, (2006a); Acosta Pereira e Rodrigues (2010), Lima (2014), Miotello (2012), Santos e Almeida (2012), Brait (2012b), Oliveira, Huff e Acosta Pereira (2019), Rodrigues (2004) e Rohling (2014). A relativa estabilidade observada em padrões linguístico-discursivos, ao ser observada e analisada, pode ser, por fim, interpretada em seu caráter genérico, com todos os elementos analíticos já produzidos engajados.

É válido também lembrar que, nesse âmbito, não há criação sem recriação. E é na compreensão da repetição e da recriação dos enunciados em seus gêneros que se observa sua relativa estabilidade (LIMA, 2014). Nesse ponto de vista, como lembram Santos e Almeida (2012), fica claro que M. Bakhtin valoriza não apenas a análise e intepretação no pequeno tempo - a atualidade, passado imediato e futuro previsível -, mas também a observância ao grande tempo - diálogo inacabável em que nenhum sentido está morto e mantém-se em viva renovação.

Para Geraldi (2012), uma interpretação aprofundada tem como resultado justamente a ampliação do contexto do enunciado ao passo que mais vozes emergem além daquelas manifestas na superfície do discurso. Emergem para dialogarem. O objetivo final da interpretação, portanto, deve ser desenvolver sentidos ao compreender ativamente a vida social do homem por meio da linguagem viva, em movimento.

Ao desenvolver sentidos, Sobral e Giacomelli (2018) lembram que a unidade do discurso deve ser respeitada. Isto é, o sentido se constrói justamente na articulação entre o linguístico e o extralinguístico - componentes inseparáveis de uma mesma unidade. E, dessa forma, também se examinam "[...] os efeitos de sentido gerados pela unidade advinda da junção entre a pertinência do tex to a uma dada discursividade e a uma dada genericidade e a textualização/textualidade específica que ele exibe" (SOBRAL, 2014, p. 32).

De mesmo modo, os elementos ligados à estabilidade e à singularidade atuam juntos na formação de sentidos em uma análise bakhtiniana. Em outras palavras, na ADD, lida-se com a relação entre os aspectos particulares e os aspectos generalizáveis do objeto, entre o repetível e o não repetível. Partindo de M. Bakhtin, Miotello (2012) concorda que o reconhecimento do caráter repetível do objeto e a descoberta do novo, não-repetível, precisam estar ligados intrinsecamente no ato vivo da compreensão. De forma semelhante, Rohling (2014) conclui, ao mencionar Ponzio (2010), que é necessária a observação do singular da enunciação, do evento único que conduz a uma certa 


\section{REVISTA DA ABRALIN}

regularidade. Isso pois o elemento singular examinado não raro reaparece de alguma forma, conduzindo o desenvolvimento de conceitos, de classificações, de conjuntos que compõem o conhecimento geral sobre determinado assunto.

Para finalizar, pode-se entender que, ao adotar a ADD, não se busca determinar definitivamente seu objeto de estudo, mas, sim, compreendê-lo de forma profunda (OLIVEIRA; HUFF; ACOSTA PEREIRA, 2019) por meio de gestos interpretativos, isto é, por meio da contínua atribuição de sentidos (SANTOS; ALMEIDA, 2012). Nessa vertente de análise, a produção de sentidos é inesgotável. Para tanto, o momento da interpretação é o de levar a investigação de respostas ao humanamente possível (SOBRAL; GIACOMELLI, 2018). Alcança-se, assim, ao fim de uma fundamentada análise bakhtiniana, uma análise não neutra do objeto em que a validade da interpretação discursiva é dada pela consistência, coerência e profundidade dos argumentos engendrados na construção de sentidos (GERALDI, 2012).

\section{Considerações finais}

Nesta revisão sistemática integrativa, a partir da síntese narrativa feita com base nos estudos reunidos, foram considerados pela incidência temática como relevantes três principais focos metodológicos para a ADD: as relações dialógicas, os gêneros e as formas da língua. E, para que se dê conta desses focos, mostraram-se recorrentes as atividades analíticas nomeadas aqui como descrição, análise e interpretação.

As ideias de descrição, análise e interpretação não são algo novo na argumentação da área científica. São termos que ressoam em obras básicas de metodologia como a de Gil (2008) e Gerhardt e Silveira (2009). No entanto, essas atividades assumem caráter único dentro da perspectiva bakhtiniana. A singularidade da ADD está no encontro constitutivo da linguística com a metalinguística. Diante disso, o pesquisador detém um posicionamento irrepetível frente ao objeto. Para o estudioso bakhtiniano, é a relação dialógica com o objeto, entre as vozes presentes e as relacionáveis com o enunciado, que garante compreender os sentidos de um texto na qualidade de enunciado vivo.

No procedimento analítico, as categorias de análise - os conceitos bakhtinianos - são mobilizadas à medida que o corpus se revela e sugere a abordagem delas. Cada corpus é diferente, portanto, cada um terá necessidades de abrangência, aprofundamento e abordagem teórica diferentes e cabe ao pesquisador, em diálogo contínuo com o objeto, decidir sobre esses fatores.

Para uma reflexão adequada, a ADD demanda, além de uma boa compreensão teórica, a adoção de procedimentos metodológicos - como os que foram aqui recuperados - de modo a produzir uma análise rigorosa, mas nunca mecânica. Sem uma metodologia, única e já dada, o diálogo com o objeto que o pesquisador conduz em suas análises compreende os focos e as atividades analíticas sempre com estilo único.

Levando todo o apresentado em consideração, esta revisão sistemática mostra-se especialmente necessária porque muito já se refletiu sobre a ADD, mas um estudo abrangente integrando o 


\section{REVISTA DA ABRALIN}

conhecimento construído ao longo de seus anos pode mostrar direções de estudo a jovens pesquisadores - um guia para suas próprias leituras integrais - e indicar, a estudiosos experientes, pontos de abordagem metodológica potencialmente frutíferos.

Como ensina a perspectiva bakhtiniana, uma revisão sistemática integrativa também nunca adquire um caráter de fechamento permanente - nem pretende tomar para si um verniz de verdade única. No momento mesmo em que é publicada, novos estudos são desenvolvidos, e vão demandar a atualização integradora dos saberes compartilhados.

\section{Agradecimentos}

Este trabalho foi realizado com apoio do CNPq, Conselho Nacional de Desenvolvimento Científico e Tecnológico - Brasil.

\section{REFERÊNCIAS}

ACOSTA PEREIRA, R.; OLIVEIRA, A. M. Análise dialógica do conteúdo temático em gêneros do discurso. Revista Educação e Linguagens, Campo Mourão-PR, v. 9, n. 16, p. 245-264, jan./jun. 2020. Disponível em:

http://www.fecilcam.br/revista/index.php/educacaoelinguagens/article/view/1970. Acesso em: 30 mar. 2021.

ACOSTA PEREIRA, R.; RODRIGUES, R. H. Os gêneros do discurso sob perspectiva da Análise Dialógica de Discurso do Círculo de Bakhtin. Letras, Santa Maria-RS, v. 20, n. 40, p. 147-162, 2010. Disponível em: https://doi.org/10.5902/2176148512149. Acesso em: 30 mar. 2021.

ALVES, M. P. C. O enunciado concreto como unidade de análise: a perspectiva metodológica bakhtiniana. In: PEREIRA, R. A.; RODRIGUES R. H. (orgs.). Estudos dialógicos da linguagem em pesquisas em Linguística Aplicada. Apresentação Rosângela Hammes Rodrigues e Rodrigo Acosta Pereira. 2. ed. São Carlos - SP: Pedro \& João, 2019. p. 163-178.

BAKHTIN, M. Metodologia das ciências humanas. In: BAKHTIN, M. Estética da Criação Verbal. Prefácio à edição francesa Tzvetan Todorov. Introdução e tradução de Paulo Bezerra. 4. ed. São Paulo: Martins Fontes, 2003. p. 393-410.

BAKHTIN, M. Para uma filosofia do ato responsável. Tradução Valdemir Miotello e Carlos Alberto Faraco. São Carlos: Pedro \& João Editores, 2010.

BAKHTIN, M. O discurso em Dostoiévski. In: BAKHTIN, M. Problemas da poética de Dostoiévski. Tradução, notas e prefácio de Paulo Bezerra. 5. ed. Rio de Janeiro: Forense Universitária, 2013. p. 207-310.

BAKHTIN, M. Os gêneros do discurso. Organização, tradução, posfácio e notas Paulo Bezerra. Notas da edição russa Serguei Botcharov. 2. ed. São Paulo: Editora 34, 2016.

BRAIT, B. As vozes bakhtinianas e o diálogo inconcluso. In: BARROS, D. L. P. de; FIORIN, J. L. (orgs.). Dialogismo, polifonia, intertextualidade: em torno de Bakhtin. São Paulo: EDUSP, 1994. p. 11-27. 


\section{REVISTA DA ABRALIN}

BRAIT, B. Ironia em perspectiva polifônica. Campinas: UNICAMP, 1996.

BRAIT, B. Análise e teoria do discurso. In: BRAIT, B. (org.). Bakhtin: outros conceitos-chave. Introdução de Beth Brait. São Paulo: Contexto, 2006a. p. 09-32.

BRAIT, B. Uma perspectiva dialógica de teoria, método e análise. Gragoatá, Niterói-RJ, n. 20, p. 47-62, 2006b. Disponível em: https://periodicos.uff.br/gragoata/article/view/33238. Acesso em: 30 mar. 2021.

BRAIT, B. Construção coletiva da perspectiva dialógica: história e alcance teórico-metodológico. In: FIGARO, R. (org.). Comunicação e análise do discurso: as materialidades do sentido. Apresentação Adilson Citelli. Introdução Roseli Figaro. São Paulo: Contexto, 2012a. p. 79-98.

BRAIT, B. Perspectiva dialógica. In: BRAIT, B.; SOUZA-E-SILVA, M. C. (orgs.). Texto ou discurso?. Apresentação Beth Brait e Maria Cecília Souza-e-Silva. São Paulo: Contexto, 2012b. p. 9-29.

BRAIT, B.; PISTORI, M. H. C. Marxismo e filosofia da linguagem: a recepção de Bakhtin e o Círculo no Brasil. Bakhtiniana, São Paulo, v. 15, n. 2, p. 33-63, abr./jun. 2020. Disponível em: http://dx.doi.org/10.1590/2176457344560. Acesso em: 30 mar. 2021.

FANINI, A. M. R. Contribuições da Análise Dialógica do Discurso para a pesquisa acadêmica. Polifonia, Cuiabá-MT, v. 26, n. 43, p. 111-129, 2019. Disponível em:

https://periodicoscientificos.ufmt.br/ojs/index.php/polifonia/article/view/7894. Acesso em: 30 mar. 2021.

FIGUEIREDO, M. H.; TREVIZAN, M. V. O problema do conteúdo, da forma e do material: orientações metodológicas. In: MIOTELLO, V. (org.). Palavras e contrapalavras: enfrentando questões da metodologia bakhtiniana. São Carlos: Pedro e João editores, 2012. p. 80-95.

GEDOZ, S. Estudo dos gêneros discursivos sob a perspectiva da Análise Dialógica do Discurso: percurso teórico e metodológico. Leitura, Maceió-AL, v. 1, n. 55, p. 145-162, 2015. Disponível em: http://www.dx.doi.org/10.28998/2317-9945.2015v1n55p145-162. Acesso em: 30 mar. 2021.

GERALDI, J. W. Heterocientificidade nos estudos linguísticos. In: MIOTELLO, V. (org.). Palavras e contrapalavras: enfrentando questões da metodologia bakhtiniana. São Carlos: Pedro e João editores, 2012. p. 19-39.

GERHARDT, T. E.; SILVEIRA, D. T. (Orgs.). Métodos de Pesquisa. Porto Alegre: Editora da UFRGS, 2009.

GIL, A. C. Métodos e técnicas de pesquisa social. 6. ed. Prefácio Antonio Carlos Gil. São Paulo: Atlas, 2008.

GRILLO, S. V. de C. Fundamentos bakhtinianos para a análise de enunciados verbo-visuais. Filologia e Linguística Portuguesa, São Paulo, v. 14, n. 2, p. 235-246, 2012. Disponível em: https://doi.org/10.11606/issn.2176-9419.v14i2. Acesso em: 30 mar. 2021.

JONES-DEVITT, S.; PARKIN, H. J. Integrative Reviewing for exploring complex phenomena. Social Research Update, United Kingdom, n. 66. p. 1-4, 2017. Disponível em: http://shura.shu.ac.uk/16571/. Acesso em: 10 jan. 2021.

LIMA, A. Procedimentos teórico-metodológicos de estudo de gêneros do discurso: atividade e oralidade em foco. In: BRAIT, B; MAGALHÃES, A. S. (orgs.). Dialogismo: teoria e(m) prática. Apresentação de Carlos Alberto Faraco. São Paulo: Terracota Editora, 2014. p. 37-53.

MARCHEZAN, R. C. Sobre o pensamento bakhtiniano: uma recepção de recepções. Bakhtiniana, São Paulo, v. 8, n. 1., p. 82-94, jan./jun. 2013. Disponível em: https://doi.org/10.1590/S2176-45732013000100006. Acesso em: 30 mar. 2021. 


\section{REVISTA DA ABRALIN}

MENDONÇA, M. C. Desafios metodológicos para os estudos bakhtinianos do discurso. In: MIOTELLO, V. (org.). Palavras e contrapalavras: enfrentando questões da metodologia bakhtiniana. São Carlos: Pedro e João editores, 2012. p. 107-117.

MIOTELLO, V. Algumas anotações para pensar a questão do método em Bakhtin. In: MIOTELLO, V. (org.). Palavras e contrapalavras: enfrentando questões da metodologia bakhtiniana. São Carlos: Pedro e João editores, 2012. p. 151-168.

NEWMAN, M.; GOUGH, D. Sistematic Reviews in Educational Research: Metodology, Perspectives and Application. In: ZAWACKI-RICHTER, O. et al (ed.). Sistematic Reviews in Educational Research: Metodology, Perspectives and Application. Germany: Springer, 2020. p. 3-22.

OLIVEIRA, A. M.; HUFF, L. de A.; ACOSTA PEREIRA, R. Considerações Teórico-Metodológicas para estudo da palavra-discurso: respostas a dois ensaios de Mikhail Bakhtin. Caminhos em Linguística Aplicada, Taubaté-SP, v. 20, n. 1, p. 131-151, 2019. Disponível em:

http://periodicos.unitau.br/ojs/index.php/caminhoslinguistica/article/view/2736. Acesso em: 30 mar. 2021.

PAULA, L. de. Círculo de Bakhtin: uma Análise Dialógica de Discurso. Revista de Estudos da Linguagem, Belo Horizonte-MG, v. 21, n. 1, p. 239-258, 2013. Disponível em: https://doi.org/10.17851/2237-2083.21.1.239-258. Acesso em: 30 mar. 2021.

PAULA, L. de; LUCIANO, J. A. R. A tridimensionalidade verbivocovisual da linguagem bakhtiniana. Linha D’Água, São Paulo, n. 33, v. 3, p. 105-134, 2020. Disponível em: https://doi.org/10.11606/issn.2236-4242.v33i3p105-134. Acesso em: 30 jul. 2021.

PAULO, S. de; MOREIRA, T. A. Acerca do método em Problemas da poética de Dostoiévski. In: MIOTELLO, V. (org.). Palavras e contrapalavras: enfrentando questões da metodologia bakhtiniana. São Carlos: Pedro e João editores, 2012. p. 50-55.

PEREIRA, S. V. M. Da Linguística à Análise Dialógica do Discurso: contribuições para os estudos da linguagem. Letras, Belém-PA, n. 8, p. 167-190, 2017. Disponível em: https://periodicos.uepa.br/index.php/ribanceira/article/view/1210/739. Acesso em: 30 mar. 2021.

PETTICREW, M.; ROBERTS, H. Systematic Reviews in the Social Sciences: a practical guide. Oxford-UK: Blackwell Publishing, 2006.

PONZIO, A. Prefácio de Para uma filosofia do ato responsável. Tradução de Carlos Alberto Faraco e Valdemir Miotello. São Carlos: Pedro \& João Editores, 2010. p. 9-38.

PONZIO, A. "Questions de méthode". A obra de Pavel Medvedev nos estudos literários e outros. In: MIOTELLO, V. (org.). Palavras e contrapalavras: enfrentando questões da metodologia bakhtiniana. São Carlos: Pedro e João editores, 2012. p. 131-150.

RODRIGUES, N. C. Trajetória de pesquisa em Ciências Humanas com aporte teórico-metodológico bakhtiniano. Calidoscópio, São Leopoldo-RS, v. 13, n. 1, p. 122-131, jan/abr 2015. Disponível em: https://doi.org/10.4013/cld.2015.131.12. Acesso em: 30 mar. 2021

RODRIGUES, R. H. Análise de gêneros do discurso na teoria bakhtiniana: algumas questões teóricas e metodológicas. Linguagem em (Dis)curso, Tubarão-SC, v. 4, n. 2, p. 415-440, 2004. Disponível em: http://www.portaldeperiodicos.unisul.br/index.php/Linguagem_Discurso/article/view/272/28. Acesso em: 30 mar. 2021. 


\section{REVISTA DA ABRALIN}

ROHLING, N. A pesquisa qualitativa e Análise Dialógica do Discurso: caminhos possíveis. Cadernos de Linguagem e Sociedade, Brasília, v. 15, n. 2, p. 44-60, 2014. Disponível em: https://doi.org/10.26512/les.v15i2.7561. Acesso em: 30 mar. 2021.

RUIZ, T. M. B. Diretrizes metodológicas na Análise Dialógica do Discurso: o olhar do pesquisador iniciante. Revista Diálogos, Sinop-MT, v. 5, n. 1, p. 39-59, 2017. Disponível em:

https://periodicoscientificos.ufmt.br/ojs/index.php/revdia/article/view/5119. Acesso em: 30 mar. 2021.

SANTOS, E. C.; ALMEIDA, M. de F. Diretrizes Bakhtinianas para o método sociológico em ciências humanas. Macabéa - Revista Eletrônica do Netlli, Crato-CE, v. 2, p. 77-92, 2012. Disponível em: https://doi.org/10.47295/mren.v1i2.395. Acesso em: 30 mar. 2021.

SCHERMA, C. C.; TURATI, C. Uma leitura do texto Estrutura do Enunciado de V. N. Volochínov (1930). In: MIOTELLO, V. (org.). Palavras e contrapalavras: enfrentando questões da metodologia bakhtiniana. São Carlos: Pedro e João editores, 2012. p. 40-49.

SOBRAL, A. Uma proposta bakhtiniana de estudos dos gêneros discursivos. In: BRAIT, B.; MAGALHÃES, A. S. (orgs.). Dialogismo: teoria e(m) prática. Apresentação de Carlos Alberto Faraco. São Paulo: Terracota Editora, 2014. p. 19-35

SOBRAL, A.; GIACOMELLI, K. Observações didáticas sobre a Análise Dialógica do Discurso - ADD. Domínios de Lingu@gem, Uberlândia-MG, v. 10, n. 3, p. 1076-1094, 26 ago. 2016. Disponível em: https://doi.org/10.14393/dl23-v10n3a2016-15. Acesso em: 30 mar. 2021.

SOBRAL, A.; GIACOMELLI, K. Das significações na língua ao sentido na linguagem: parâmetros para uma Análise Dialógica. Linguagem e(m) Discurso, Tubarão-SC, v. 18, n. 2, p. 307-322, 2018. Disponível em: https://doi.org/10.1590/1982-4017-180203-9317. Acesso em: 30 mar. 2021.

STAFUZZA, G. B. O Círculo de Bakhtin (Volóchinov e Medviédev) no Brasil. Revista Heterotópica, Goiânia-GO, v. 1, n. 1, p. 66-82, 26 jun. 2019. Disponível em: https://doi.org/10.14393/HTP-v1n1-2019-48519. Aceso em: 30 mar 2021

TODOROV, T. Mikhaïl Bakhtine: le principe dialogique suivi de écrits du Cercle de Bakhtine. Paris: Éditions de Seuil, 1981

TREVIZAN, M. V. Perspectivas metodológicas em Marxismo e Filosofia da Linguagem. In: MIOTELLO, V. (org.). Palavras e contrapalavras: enfrentando questões da metodologia bakhtiniana. São Carlos: Pedro e João editores, 2012. p. 118-130.

VICTOR, L. Systematic reviewing. Social Research Update, United Kingdom, n. 54., p. 1-4, 2008. Disponível em: https://sru.soc.surrey.ac.uk/SRU54.pdf. Acesso em: 10 jan. 2021.

VOLÓCHINOV, V (Círculo de Bakhtin). Marxismo e filosofia da linguagem: Problemas fundamentais do método sociológico na ciência da linguagem. Tradução, notas e glossário de Sheila Grillo e Ekaterina Vólkova Américo; ensaio introdutório de Sheila Grillo. São Paulo: Editora 34, 2017.

ZOHURI, B.; MOGHADDAM, M. What Is Boolean Logic and How It Works. In: ZOHURI B.; MOGHADDAM, M. Business Resilience System (BRS): Driven Through Boolean, Fuzzy Logics and Cloud Computation. Alemanha: Springer International Publishing, 2017. p. 183-198. 


\section{REVISTA DA ABRALIN}

Apêndice A - Protocolo de busca e os resultados das etapas de seleção

\begin{tabular}{|c|c|c|c|c|c|}
\hline Fontes & Estratégia de busca & $\begin{array}{l}\text { Resul- } \\
\text { tado ini- } \\
\text { cial }\end{array}$ & $\begin{array}{l}\text { Seleção } \\
\text { título }\end{array}$ & $\begin{array}{l}\text { Seleção } \\
\text { resumo }\end{array}$ & $\begin{array}{l}\text { Seleção } \\
\text { texto inte- } \\
\text { gral }\end{array}$ \\
\hline $\begin{array}{l}\text { Database: Go- } \\
\text { ogle Acadê- } \\
\text { mico }\end{array}$ & $\begin{array}{l}\text { Título: "Análise dialógica do discurso" OR "Análise do discurso bakhtiniana" } \\
\text { OR "Análise de discurso bakhtiniana" OR "Análise Bakhtiniana" OR "Teoria } \\
\text { bakhtiniana" OR "Análise dialógica" OR "Teoria dialógica" OR "Perspectiva } \\
\text { dialógica" }\end{array}$ & 535 & 25 & 13 & 13 \\
\hline \multirow[t]{2}{*}{$\begin{array}{l}\text { Database: } \\
\text { Portal de Pe- } \\
\text { riódicos Ca- } \\
\text { pes }\end{array}$} & $\begin{array}{l}\text { Título: "Análise dialógica do discurso" OR "Análise do discurso bakhtiniana" } \\
\text { OR "Análise de discurso bakhtiniana" OR "Análise Bakhtiniana" OR "Teoria } \\
\text { bakhtiniana" OR "Análise dialógica" OR "Teoria dialógica" OR "Perspectiva } \\
\text { dialógica" } \\
\text { Caixas selecionadas: revisado por pares e idioma português }\end{array}$ & 227 & 2 & 0 & 0 \\
\hline & $\begin{array}{l}\text { Título: Metodologia OR Método OR Prática OR metodológico OR } \\
\text { metodológica OR Teórico-metodológico OR Teórico-metodológica OR } \\
\text { Epistem* OR Parâmetro } \\
\text { Qualquer: "Análise dialógica do discurso" OR "Análise do discurso } \\
\text { bakhtiniana" OR "Análise de discurso bakhtiniana" OR "Análise Bakhtiniana" } \\
\text { OR "Teoria bakhtiniana" OR "Análise dialógica" OR "Teoria dialógica" OR } \\
\text { "Perspectiva dialógica" } \\
\text { Caixas selecionadas: revisado por pares e idioma português }\end{array}$ & 10 & 2 & 2 & 2 \\
\hline $\begin{array}{l}\text { Database: Sci- } \\
\text { ELO }\end{array}$ & $\begin{array}{l}\text { Título: ("Análise dialógica do discurso" OR "Análise do discurso bakhtiniana" } \\
\text { OR "Análise de discurso bakhtiniana" OR "Análise Bakhtiniana" OR "Teoria } \\
\text { bakhtiniana" OR "Análise dialógica" OR "Teoria dialógica" OR "Perspectiva } \\
\text { dialógica") }\end{array}$ & 25 & 5 & 1 & 1 \\
\hline $\begin{array}{l}\text { Database: Go- } \\
\text { ogle Books }\end{array}$ & $\begin{array}{l}\text { Todos os índices: ("Análise dialógica do discurso" OR "Análise do discurso } \\
\text { bakhtiniana" OR "Análise Bakhtiniana" OR "Teoria bakhtiniana" OR "Análise } \\
\text { dialógica" OR "Teoria dialógica" OR "Perspectiva dialógica") AND (Metodolo- } \\
\text { gia OR Método OR Prática OR metodológico OR metodológica OR Teórico- } \\
\text { metodológico OR Teórico-metodológica OR Epistem* OR Parâmetro) }\end{array}$ & 180 & 4 & - & 0 \\
\hline $\begin{array}{l}\text { Database: } \\
\text { Portal de pe- } \\
\text { riódico Capes } \\
\text { (livros) }\end{array}$ & $\begin{array}{l}\text { Título: "Análise dialógica do discurso" OR "Análise do discurso bakhtiniana" } \\
\text { OR "Análise de discurso bakhtiniana" OR "Análise Bakhtiniana" OR "Teoria } \\
\text { bakhtiniana" OR "Análise dialógica" OR "Teoria dialógica" OR "Perspectiva } \\
\text { dialógica" }\end{array}$ & 0 & 0 & - & 0 \\
\hline $\begin{array}{l}\text { Database: Sci- } \\
\text { ELO Livros }\end{array}$ & $\begin{array}{l}\text { Todos os índices: "Análise dialógica do discurso" OR "Análise do discurso } \\
\text { bakhtiniana" OR "Análise de discurso bakhtiniana" OR "Análise Bakhtiniana" } \\
\text { OR "Teoria bakhtiniana" OR "Análise dialógica" OR "Teoria dialógica" OR } \\
\text { "Perspectiva dialógica" } \\
\text { Caixa selecionada: books and books chapters }\end{array}$ & 2 & 0 & - & 0 \\
\hline $\begin{array}{l}\text { Database: } \\
\text { Wordcat (li- } \\
\text { vros) }\end{array}$ & $\begin{array}{l}\text { Título: "Análise dialógica do discurso" OR "Análise do discurso bakhtiniana" } \\
\text { OR "Análise de discurso bakhtiniana" OR "Análise Bakhtiniana" OR "Teoria } \\
\text { bakhtiniana" OR "Análise dialógica" OR "Teoria dialógica" OR "Perspectiva } \\
\text { dialógica" } \\
\text { Caixas selecionadas: formato livro e idioma português }\end{array}$ & 14 & 0 & - & 0 \\
\hline $\begin{array}{l}\text { Diretório de } \\
\text { Grupos de } \\
\text { Pesquisa } \\
\text { (DGP) - CNPq }\end{array}$ & $\begin{array}{l}\text { Busca "Bakhtin" ou "bakhtiniano" ou "bakhtiniana" com as caixas "Nome do } \\
\text { grupo", "Nome da linha de pesquisa", "Palavra-chave da linha de pesquisa" e } \\
\text { "Repercussões do grupo" selecionadas. Os grupos da área de Letras e Lin- } \\
\text { guística somaram } 55 . \\
\text { Os currículos Lattes dos } 94 \text { líderes desses grupos foram investigados ma- } \\
\text { nualmente com as palavras de busca já mencionadas. }\end{array}$ & - & $\begin{array}{l}8 \text { Artigos } \\
6 \text { Livros } \\
8 \text { Capítu- } \\
\text { los }\end{array}$ & - & $\begin{array}{l}7 \text { Artigos } \\
13 \text { Capítu- } \\
\text { los }\end{array}$ \\
\hline \multicolumn{6}{|c|}{ Resultados atualizados em 30 mar. 2021 | Total geral: 36 | Total sem duplicatas: 30} \\
\hline
\end{tabular}




\section{REVISTA DA ABRALIN}

Apêndice B - Quadro de resultados-chave das etapas de codificação e avaliação

\begin{tabular}{|c|c|c|c|c|c|c|c|}
\hline \multirow{2}{*}{ Textos do corpus } & \multirow{2}{*}{$\begin{array}{l}\text { Ori- } \\
\text { gem }\end{array}$} & \multicolumn{3}{|c|}{ Codificação: foco } & \multicolumn{3}{|c|}{ Codificação: atividades analíticas } \\
\hline & & $\begin{array}{l}\text { Relações dia- } \\
\text { lógicas }\end{array}$ & $\begin{array}{c}\text { Gêneros do } \\
\text { discurso }\end{array}$ & $\begin{array}{c}\text { Formas da } \\
\text { língua }\end{array}$ & Descrição & Análise & Interpretação \\
\hline RODRIGUES, 2004 & . & $\checkmark$ & $\checkmark$ & $\checkmark$ & $\checkmark$ & $\checkmark$ & $\checkmark$ \\
\hline BRAIT, 2006a & $\Delta$ & $\checkmark$ & $\checkmark$ & $\checkmark$ & $\checkmark$ & $\checkmark$ & $\checkmark$ \\
\hline BRAIT, 2006b & -14 & $\checkmark$ & $\checkmark$ & $\checkmark$ & & $\checkmark$ & $\checkmark$ \\
\hline ACOSTA-PEREIRA; RODRIGUES, 2010 & - & $\checkmark$ & $\checkmark$ & $\checkmark$ & & $\checkmark$ & $\checkmark$ \\
\hline BRAIT, 2012a & $\Delta$ & $\checkmark$ & $\checkmark$ & $\checkmark$ & $\checkmark$ & $\checkmark$ & $\checkmark$ \\
\hline BRAIT, 2012b & $\Delta$ & $\checkmark$ & $\checkmark$ & $\checkmark$ & & $\checkmark$ & $\checkmark$ \\
\hline FIGUEIREDO; TREVISAN, 2012 & $\Delta \cdot$ & $\checkmark$ & & & & $\checkmark$ & $\checkmark$ \\
\hline GERALDI, 2012 & $\Delta \cdot \boldsymbol{\bullet}$ & $\checkmark$ & & & $\checkmark$ & $\checkmark$ & $\checkmark$ \\
\hline MENDONÇA, 2012 & $\Delta \cdot$ & $\checkmark$ & & & & & $\checkmark$ \\
\hline MIOTELLO, 2012 & $\Delta \cdot$ & $\checkmark$ & $\checkmark$ & $\checkmark$ & $\checkmark$ & $\checkmark$ & $\checkmark$ \\
\hline PAULO; MOREIRA, 2012 & $\Delta \cdot$ & $\checkmark$ & & & $\checkmark$ & & \\
\hline PONZIO, 2012 & $\Delta \cdot$ & $\checkmark$ & $\checkmark$ & & $\checkmark$ & & $\checkmark$ \\
\hline SANTOS; ALMEIDA, 2012 & $\Delta$ & $\checkmark$ & & $\checkmark$ & $\checkmark$ & $\checkmark$ & $\checkmark$ \\
\hline SCHERMA; TURATI, 2012 & $\Delta \cdot$ & $\checkmark$ & $\checkmark$ & $\checkmark$ & & & $\checkmark$ \\
\hline TREVIZAN, 2012 & $\Delta \cdot$ & $\checkmark$ & $\checkmark$ & $\checkmark$ & & & $\checkmark$ \\
\hline PAULA, 2013 & - $\mathbf{\Delta}$ & $\checkmark$ & & & $\checkmark$ & $\checkmark$ & $\checkmark$ \\
\hline LIMA, 2014 & $\Delta \cdot$ & $\checkmark$ & $\checkmark$ & $\checkmark$ & $\checkmark$ & $\checkmark$ & $\checkmark$ \\
\hline ROHLING, 2014 & - 1 & $\checkmark$ & & & $\checkmark$ & $\checkmark$ & $\checkmark$ \\
\hline SOBRAL, 2014 & $\Delta \cdot$ & $\checkmark$ & $\checkmark$ & $\checkmark$ & $\checkmark$ & $\checkmark$ & $\checkmark$ \\
\hline GEDOZ, 2015 & - & $\checkmark$ & $\checkmark$ & $\checkmark$ & & & \\
\hline RODRIGUES, 2015 & - & $\checkmark$ & $\checkmark$ & & $\checkmark$ & $\checkmark$ & $\checkmark$ \\
\hline ALVES, 2019 [2016] & $\Delta$ & $\checkmark$ & $\checkmark$ & & & $\checkmark$ & \\
\hline SOBRAL; GIACOMELLI, 2016 & -1 & $\checkmark$ & $\checkmark$ & $\checkmark$ & $\checkmark$ & $\checkmark$ & $\checkmark$ \\
\hline PEREIRA, 2017 & - & $\checkmark$ & & $\checkmark$ & & $\checkmark$ & \\
\hline RUIZ, 2017 & - & $\checkmark$ & $\checkmark$ & $\checkmark$ & $\checkmark$ & $\checkmark$ & \\
\hline SOBRAL; GIACOMELLI; 2018 & - $\Delta$ & $\checkmark$ & $\checkmark$ & $\checkmark$ & $\checkmark$ & $\checkmark$ & $\checkmark$ \\
\hline FANINI, 2019 & - $\Delta$ & $\checkmark$ & & & $\checkmark$ & $\checkmark$ & $\checkmark$ \\
\hline OLIVEIRA; HUFF; ACOSTA PEREIRA, 2019 & - & $\checkmark$ & & $\checkmark$ & $\checkmark$ & $\checkmark$ & $\checkmark$ \\
\hline STAFUZZA, 2019 & - & $\checkmark$ & $\checkmark$ & $\checkmark$ & & $\checkmark$ & $\checkmark$ \\
\hline ACOSTA PEREIRA; OLIVEIRA, 2020 & - & $\checkmark$ & $\checkmark$ & $\bar{\checkmark}$ & & $\checkmark$ & \\
\hline
\end{tabular}

